\title{
Clorprenaline Hydrochloride
}

National Cancer Institute

\section{Source}

National Cancer Institute. Clorprenaline Hydrochloride. NCI Thesaurus. Code C65343.

The hydrochloride salt form of clorprenaline, a beta- 2 adrenergic agonist with bronchodilator activity. Clorprenaline selectively binds to and activates beta-2 adrenergic receptors in bronchiolar smooth muscle, thereby causing stimulation of adenyl cyclase, the enzyme that catalyzes the conversion of adenosine triphosphate (ATP) to cyclic-3',5'adenosine monophosphate (CAMP). Increased intracellular CAMP levels cause relaxation of bronchial smooth muscle. This increases air flow and prevents bronchospasms and may eventually lead to an improvement of airway function. 